\section{Comunicación de errores médicos a pacientes y familiares: interrogantes $y$ herramientas}

\author{
MARÍA LUZ BASCUÑÁN ${ }^{1, \mathrm{a}, \mathrm{b}}$, ANA MARÍA ARRIAGADA
}

\section{Communication of medical errors to patients: questions and tools}

For several years and in many different ways, medical errors have been studied. As expected, the majority of efforts have been directed to prevent clinical errors during the different phases of health care. Nevertheless, less attention has been given to what happens when a negative effect has already occurred. The present work describes the doubts and difficulties that doctors deal with when facing an error and to describe the communicational tools that the literature offers to cope with them. The definition of medical error was the starting point that was used to later analyze the evidence about what, why and how to inform medical errors from an ethical and technical point of view. In the light of new legal exigencies, communicational and health protocols are revised, distinguishing those that are used for conveying bad news and medical errors. The importance of the ethical and communicational formation of the professionals is emphasized, identifying certain hindering aspects of the medical culture. This culture promotes an idea of the doctor as a professional who knows everything, does not make mistakes and acts in isolation. These do not reflect personal attributes in the professional and in the health team, required for a good professional practice.

(Rev Med Chile 2016; 144: 1185-1190)

Key words: Communication; Disclosure; Ethics; Medical Errors.
'Universidad de Chile, Facultad de Medicina. Departamento de Bioética y Humanidades Médicas. Santiago, Chile.

${ }^{2}$ Hospital del Salvador. apsicóloga.

${ }^{\mathrm{b} P h D}$.

Recibido el 14 de octubre de 2015, aceptado el 22 de marzo de 2016.

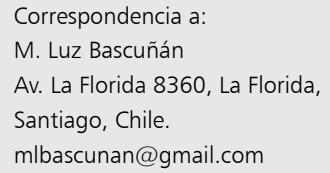

$\mathrm{E}$ 1 informe del Institute of Medicine titulado "To err is Human" (1999) fue un gran impulsor de la actual preocupación por la seguridad clínica y calidad de la atención a los pacientes". En este documento se define "error médico" como la falla en la ejecución de una acción adecuadamente planificada o el uso de un plan equivocado para lograr un objetivo. Por su parte, evento adverso (EA) se entiende como el daño producido a los pacientes de manera directa $\mathrm{o}$ indirecta por la atención médica. Si bien todo evento adverso es resultado del manejo médico (y no debido a la condición del paciente) no todos son prevenibles, es decir, atribuibles a un error. Es decir, todo error constituye un evento adverso pero no todo evento adverso es producto de un error.
Este informe ubica las muertes por errores médicos (EM) entre las ocho principales causas de muerte en Estados Unidos de Norteamérica. Estudios posteriores y en distintos continentes han confirmado la alta frecuencia de eventos adversos (EA) siendo gran parte de ellos prevenibles (es decir, errores) $)^{2}$.

De allí que la mayor parte de los esfuerzos se han orientado a investigar e intervenir para evitar la ocurrencia de EA en las distintas fases de la atención de salud. Sin embargo, y aunque igualmente importante, menos atención hemos dado a lo que sucede cuando un evento adverso ya ha ocurrido.

En el presente trabajo nos proponemos revisar algunas de las interrogantes y dificultades que 
experimentan los médicos cuando enfrentan un evento adverso prevenible o error así como describir las herramientas comunicacionales que la literatura nos ofrece para enfrentarlas.

\section{¿Comunicamos o callamos?}

De acuerdo a la revisión de la literatura realizada por Mazor, Simon y Gurwitz ${ }^{3}$, existe suficiente evidencia respecto a que los EA y EM frecuentemente no se comunican, que el público cree que deben comunicarse y que los médicos comparten esta opinión pero carecen de información que les guíe respecto a qué, cuándo y cómo hacerlo.

En efecto, diversos estudios muestran que los médicos creen que es correcto comunicar un error, pero no lo hacen, y que los pacientes no sólo desean ser informados de las causas y consecuencias de los errores, sino que esperan disculpas y apoyo emocional $^{4,5}$.

Actualmente la decisión de comunicar o callar no es sólo asunto del profesional. La legislación así como las agencias reguladoras y acreditadoras han determinado el deber de informar transparentemente todo evento adverso al paciente. Este es el caso de Chile desde el año 2012 cuando entró en vigencia la Ley 20.584 que Regula los Derechos y Deberes que tienen las personas en Relación con acciones vinculadas a su Atención en Salud ${ }^{6}$.

Pero la ley no soluciona todos los problemas. Del hecho de establecer un deber no se desprende que éste se cumpla ni que se cumpla adecuadamente. La reflexión sobre los fundamentos éticos de un deber permiten a hacer sentido del mismo y considerarlo como un compromiso con la profesión. Aun cuando la ley, la ética, los usuarios y los mismos profesionales concuerdan con que debe comunicarse los errores, persisten las dificultades respecto a cómo hacerlo.

\section{¿Qué comunicar y qué consecuencias tiene lo comunicado?}

El principal obstáculo para comunicar errores médicos es la anticipación de las consecuencias que traerá y a nuestros sentimientos de miedo, culpa y vergüenza. Se teme a las reacciones emocionales y conductuales de los pacientes y familiares, así como a ser sancionado por los co- legas, a perder la reputación y confianza, y a ser demandado legalmente ${ }^{7,8}$.

Como sostiene Berlin 9 si bien compartimos la prescripción judeo cristiana de informar, disculparse y compensar nuestros errores; éstas han sido desestimadas en numerosas instituciones de salud en tanto las disculpas (como declaraciones auto-inculpadoras) pueden usarse en las cortes de justicia. El autor cita diversos artículos que recomiendan cuidar nuestras palabras para evitar los pleitos legales por ejemplo expresando empatía y pesar pero sin admitir faltas ni responsabilidades.

Sin embargo, la evidencia no ha demostrado que exista una relación entre la comunicación de un error y el litigio. Por el contrario los datos tienden a mostrar que las explicaciones, disculpas, reconocimiento y responsabilidad por el daño inflingido disminuyen la probabilidad de una demanda legal ${ }^{10,11}$

La decisión de iniciar un proceso judicial se ha asociado a la omisión de información, la manera (clara-confusa, empática-distante) y momento de recibir las explicaciones, el tipo de daño, la situación económica del paciente y la relación médico-paciente ${ }^{12}$. Por ejemplo, Beckman y col. (1994) encontraron que en $71 \%$ de casos de demandas legales existía problemas en la relación clínica incluyendo: abandono (32\%), devaluación (29\%), falta de información (26\%), y desconsideración de la perspectiva del paciente y su familia (13\%). En este estudio 39\% de los demandantes, señaló que no habría seguido tal curso de acción si hubiese recibido una explicación y una disculpa ${ }^{13}$.

Más allá de la evidencia empírica, desde un punto de vista ético el criterio consecuencialista según el cual se recomienda "ante la duda (de lo que hará el paciente), abstente (de inculparte)", es cuestionable, pues procura el bien del médico o centro de salud implicado, en vez del interés del paciente y su familia. Avalar el ocultamiento de la información como conducta defensiva, sería una falta de respeto no sólo al paciente sino que también a los propios médicos, su ética profesional y capacidad de enfrentar los aspectos complicados de su profesión. Ya que a pesar de todas las medidas implementadas, se cometen y seguirán cometiendo errores, parece ser necesario revisar nuestras expectativas desde un enfoque más comprensivo que punitivo para lograr revertir el clima de desconfianza imperante ${ }^{14,15}$. 


\section{Desde la exigencia a la formación}

La dificultad de comunicar errores médicos no se limita al temor a las demandas legales. Existiría una cultura médica que es reticente a las fallas ${ }^{16}$. Se ha sugerido la existencia de una serie de mitos respecto a los médicos incluyendo el que deben saberlo todo, no cometer errores y que no se ven afectados por necesidades, emociones ni enfermedades. Estas creencias irracionales serían sostenidas por usuarios y profesionales, idealizando la profesión, negando las dificultades y generando frustración en todos.

La cultura médica ha sido caracterizada por la exigencia y el silencio ${ }^{17}$. Ésta se iría adquiriendo tempranamente en los años de formación bajo lemas como "siempre se puede dar más" y "no es admisible la equivocación". Se aprendería muy pronto a evadir cualquier dificultad y ante la aflicción la regla sería callar y aislarse.

En un estudio cualitativo realizado en Chile ${ }^{18}$, se encontró que para los médicos participantes la comunicación de "malas noticias" es una práctica frecuente y difícil, que se trata de evitar y para la cual no se ha recibido formación. Consistentemente se carecía de un procedimiento respecto a quién y cómo comunicar un evento adverso debiendo cada uno hacerlo de acuerdo a su intuición.

Formamos parte de la cultura de la exigencia y el silencio si suponemos que los médicos deban hacer tareas para las cuales no se han preparado. Aún cuando sabemos que el proceso de comunicación de eventos adversos es complejo para los médicos y puede generar daño en los pacientes, tradicionalmente se ha dejado en manos del sentido común ${ }^{19}$. En este contexto surge el área de Comunicación en Salud ${ }^{20,21}$. Ésta constituye una herramienta al servicio de la ética profesional en tanto determinar qué es lo correcto a hacer debe acompañarse de una reflexión sobre cómo hacerlo. Por ejemplo, estimamos que es correcto decir la verdad pero también sabemos que la manera de comunicarla determinará el tipo de experiencia (beneficiosa o dañina) que tenga el paciente.

\section{¿Cómo comunicar un error?}

Se han propuesto diversos procedimientos o guías de comunicación que han beneficiado tanto a los pacientes como a los médicos ${ }^{22,23}$. Específi- camente para enfrentar "conversaciones difíciles" con pacientes y familiares, R. Buckman ${ }^{24}$ elaboró una serie de protocolos, incluyendo aquellos para comunicar malas noticias (SPIKES), errores médicos (CONES), para resolver conflictos (HARD) y para solicitar una autopsia o donación de órganos (CONERS).

El protocolo para la CMN estructura el proceso en 6 pasos que son resumidos en el acrónimo SPIKES (traducido al español como EPICEE): 1) Entorno (preparación personal y del lugar); 2) Percepción del paciente sobre su condición; 3) Invitación a recibir información (deseo y capacidad de recibir información); 4) Conocimiento (entrega de información); 5) Exploración y acogida de los sentimientos y 6) Estrategia futura.

Cuando la mala noticia es un error, así como con las urgencias donde no se dispone de tiempo para preparar al paciente ni esperar que de él surja el interés de preguntar o saber sobre situación, la revelación de información se ofrece en un momento coyuntural que es desde el comienzo declarado como serio y preocupante por el profesional. El lema de "escuche y pregunte antes de hablar" propio de las guías para la comunicación de malas noticias ahora sería "hable y luego escuche y acoja".

Como se ilustra en la Figura 1, el protocolo para comunicación de errores médicos CONES, es una variante del SPIKES e incluye 5 pasos. Traducimos este protocolo al español con el acrónimo de esta CANEP correspondientes al Contexto (Context), Apertura (Opening remark), Narrativa (Narrative), Emociones (Emotions) y Plan y Resumen (Strategy and Summary).

\begin{tabular}{|c|c|}
\hline EPICEE (SPIKES) & CANEP (CONES) \\
\hline \multicolumn{2}{|c|}{ Entorno $\longrightarrow$ Contexto } \\
\hline Percepción & Apertura \\
\hline Invitación & \\
\hline \multicolumn{2}{|c|}{ Conocimiento $\longrightarrow$ Narrativa } \\
\hline $\begin{array}{r}\text { Exploración y acogida de } \\
\text { emociones }\end{array}$ & Emociones \\
\hline Estrategia y conclusiones & Plan y resumen \\
\hline
\end{tabular}

Figura 1. Síntesis de protocolo para la comunicación de malas Noticias y errores Médicos de R. Buckman. 
Como puede observarse, en ambos protocolos el primer y último paso son similares y el manejo de las emociones transversal a todo el proceso comunicativo.

En primer lugar, es necesario establecer un contexto apropiado. Idealmente un lugar privado donde puedan sentarse médico y paciente o familiares. La preparación del profesional no sólo implica tener conocimiento del paciente y de lo ocurrido sino que también es emocional. Se recomienda estar calmado o al menos aparentar estarlo y evitar iniciar la conversación en estado de alarma. Subyace la idea de estar lo suficientemente tranquilo y conectado, como para trasmitir calma y expresar interés por la persona.

La apertura corresponde a una declaración inicial que define el objetivo del encuentro y demuestra que usted está preparado para discutir una situación importante. Si el interlocutor ya conoce la situación se recomienda comenzar reconociéndola y lamentándola. A diferencia del protocolo para la $\mathrm{CMN}$, aquí es el informante (no el receptor) quien establece la agenda de la conversación desde un inicio. A la base está la idea de trasmitir al paciente o su familia que el profesional representando a la institución está preocupado y que se abordará el evento con la seriedad que amerita. Por lo mismo se sugiere que quien comunique el error sea el profesional de mayor jerarquía a cargo del cuidado del paciente.

Una vez establecido el motivo y contenido de la conversación se procede a explicar la secuencia de los hechos ocurridos a través de una narrativa. Esta posee el doble objetivo de ofrecer un recuento lógico cronológico de los eventos y de responder a las interrogantes y sentimientos que emergen. A medida que se va informando, el paciente y/o su familia va reaccionando y a medida que reaccionan ante la información, el profesional va respondiendo a las dudas y a las reacciones emocionales.

Según Buckman para el manejo emocional (E) debemos: 1. Identificar la emoción principal entre las diversas que se experimentan al mismo tiempo; 2. Determinar el motivo de la emoción y 3. Responder empáticamente vinculando la emoción al motivo y legitimando en vez de enjuiciar su existencia.

Las personas varían en sus reacciones y capacidad de asimilar los eventos adversos, no obstante es esperable que ante un error médico predomine la rabia e indignación. Si entendemos que estas emociones son parte del proceso de recepción de información adversa podremos manejarlas de una mejor manera.

Ante la información adversa, se identifica básicamente tres fases: Recepción, Elaboración y Adaptación. Usualmente la recepción de información implica un primer momento de shock, impresión y negación acompañado de una sensación de irrealidad. "No puede ser, esto no puede estar pasando". El golpe emocional puede ser tan fuerte que se genera un "bloqueo post-información" que no permite comprender ni registrar (escuchar) lo que se oye. La expresión de rabia indicaría que ya se comienza a reaccionar ante la información.

Palatinamente se va haciendo realidad o "digiriendo" el hecho. Las distintas emociones experimentadas son expresión de este proceso de asimilación.

Entonces, ¿qué puede hacer el profesional con estas emociones? En primer lugar, permitir que sean expresadas. Ya el hecho de no interrumpir al paciente y dejarlo manifestarse, le ayuda a "digerir" la situación. En la medida que se van procesando las emociones, van cesando y permitiendo que la persona comience a "pensar" en lo ocurrido y planificar una acción a futuro. En la tercera fase de aceptación, la se va persona adaptando y resignando a los hechos. Esto no significa que no se experimenten emociones ni que surjan abruptos de rabia o pena, ya que proceso no es lineal y toma mucho tiempo. Por lo tanto, no podemos suponer que se cierre la entrevista con una plena aceptación de los hechos. Más bien se espera que la formulación de un plan de acción conjunto contribuya a este proceso de elaboración.

$\mathrm{Al}$ resumir lo acordado y explicitar un plan se manifiesta que el profesional y la institución no abandonarán al paciente. Lo central es el compromiso del profesional, la alianza de trabajo y la seguridad de que no se actuará por intereses ajenos al paciente. Es decir, el profesional y el paciente no se encuentran en bandos opuestos sino que son aliados que persiguen un mismo objetivo.

\section{Del aislamiento a la colaboración}

En el año 2001, R. Epstein ${ }^{25}$ recomienda reemplazar la afirmación que Peabody hiciera en 1927 "el secreto del cuidado del paciente radica en ser devoto a su cuidado" por la siguiente: "el 
secreto de cuidar al paciente radica en cuidar al profesional para que le cuide".

Actualmente podríamos sugerir que "el secreto del cuidado del paciente y el profesional es contar con un equipo de trabajo".

Nos ha tomado tiempo reconocer que la herramienta privilegiada que poseen los médicos para realizar su trabajo es su propia persona ${ }^{26}$. Difícilmente podemos suponer que un médico emocionalmente vulnerable, pueda atender a las reacciones emocionales de los pacientes y enfrentar sus propias fallas sin derrumbarse. Si los médicos permanentemente se utilizan a sí mismos como instrumento diagnóstico y terapéutico, es necesario su auto-conocimiento y auto-cuida$\mathrm{do}^{27,28}$.

Sin embargo, la experiencia nos muestra que hay tareas que difícilmente pueden enfrentarse en aislamiento. Así como esperamos que el profesional cuide de si y sea capaz de contener a los pacientes; para hacerlo requiere de un sistema que lo contenga. La cohesión y comunicación del equipo de salud y el apoyo institucional son determinantes en la manera en que el profesional enfrenta los aspectos complejos de su profesión.

\section{Referencias}

1. Institute of Medicine. To err is human: building a safer health system. Washington, DC: National Academy Press; 1999.

2. Gallagher TH, Studdert D, Levinson W. Disclousing harmful medical errors to patients. N Engl J Med 2007; 356: 2713-9.

3. Mazor K, Simon S, Gurwitz J. Communicating With Patients About Medical Errors A Review of the Literature. Arch Intern Med 2004; 164 (15): 1690-7.

4. Kaldjian LC, Jones EW, Wu BJ, Forman-Hoffman VL, Levi BH, Rosenthal GE. Disclosing medical errors to patients: attitudes and practices of physicians and trainees. J Gen Intern Med 2007; 22 (7): 988-96.

5. Gallagher TH, Waterman AD, Ebers AG, Fraser VJ. Levinson W. Patients and Patirents' and Physicians' Attitudes Regarding the Disclosure of Medical Errors. JAMA 2003; 289 (8):1001-7.

6. Ministerio de Salud. Subsecretaría de Salud Pública: Ley 20.584, "Regulación de los Derechos y Deberes que tienen las personas en Relación con acciones vinculadas a su Atención en Salud". En http://www.leychile. $\mathrm{cl} / \mathrm{N} ? \mathrm{i}=1039348 \& \mathrm{f}=2012-10-01 \& \mathrm{p}$
7. Alves de Lima A. ¿Cómo comunicar malas noticias a nuestros pacientes y no morir en el intento? Rev Argentina de Cardiología 2003; 71: 217-20.

8. Yardley IS, Wu A. How to discuss errores and adverse events with cáncer patents. Current Oncology Reports 2010, Vol. 12, Issue 4: 253-60.

9. Berlin L. Will Saying "I'm Sorry" Prevent a Malpractice Lawsuit? AJR 2006; 187: 10-5.

10. Robbennolt J. Apologies and Medical Error. Clin Orthop Relat Res 2009; 467 (2): 376-82.

11. Hingorani M, Wong T, Vafidis G. Patients' and doctors' attitudes to amount of information given after unintended injury during treatment: cross sectional, questionnaire survey. BMJ 1999; 318: 640-1.

12. Vincent C, Young M, Phillips. A Why do people sue doctors? a study of patients and relatives taking legal action. Lancet 1994; 343: 1609-13.

13. Beckman HB, Markakis KM, Suchman AL, Frankel RM. The doctor-patient relationship and malpractice: lessons from plaintiff depositions. Arch Intern Med 1994; 154: 1365-70.

14. Jawahar K, Massey KL, Mulla A. Disclosue of medical error: policies and practice. J R Soc Med 2005; 98 (7): 307-9.

15. Vincent CA, Coulter A. Patient safety: what about the patient? Qual Saf Health Care 2002; 11: 76-80.

16. Robbennolt JK. Apologies and Medical Error. Clinical Orthopaedics and Related Research 2009; 467 (2): 37682.

17. Arenas-Monreal L, Hernández I, Valdez R y Bonilla P. Las instituciones de salud y el autocuidado de los médicos. Salud Pública Méx 2004; Vol. 46 (4): 326-32.

18. Bascuñán ML, Roizblatt A, Roizblatt D. Comunicación de malas noticias. Un estudio exploratorio. Rev Med Univ Navarra 2007; 51 (2): 28-31.

19. Epstein R. Comunicación en el Siglo XXI, I Simposium de Comunicación en Salud. Santiago-Chile, noviembre; 2005.

20. Maguire P, Pitceathly C. Key Communication Skills and how to acquire them. BMJ 2002; 325: 697-700.

21. Kurtz S, Silverman J, Draper J. Teaching and Learning Communication skills in medicine. Oxford: Radcliffe Publishing; 2005.

22. Stroud L, Wong B, Hollenberg E y Levinson, W. Teaching Medical Error Disclosure to Physicians-in-Training: A Scoping Review. Academic Medicine 2013; 88 (6): 884-92.

23. Ahmady A, Sabounchi S, Mirmohammadsadeghi H, Rezaei A. A Suitable Model for Breaking Bad News: Review of Recommendations. JMED Research 2014; Vol. 2014. ID 776618, DOI: 10.5171/2014.776618. 
24. Buckman R. Difficult Conversations in Medicine 2010. EE. UU: The John Hopkins University press; 2010.

25. Epstein R. Comunicación, burnout y resultados clínicos: más preguntas que respuestas. Atención Primaria 2001; 27 (7): 511-3.

26. Zoppi K, Epstein R. Is Communication a skill? Communication behaviors and being in relation. Fam Med 2002;
34 (5): 319-24.

27. Novack, DH Calibrando al medic. Conocimiento personal y cuidado eficaz del paciente. JAMA 1987; 278 (6): 502-9.

28. Gracia D. Medice, cura te ipsum. Sobre la salud física y mental de los profesionales sanitarios. Discurso sesión inaugural Real Academia Nacional de Medicina de España; 2004. 